\title{
PENDIDIKAN ISLAM \\ PERSPEKTIF TGKH. MUHAMMAD ZAENUDIN ABDUL MADJID AL ANFANANI
}

\author{
Sunardi \\ Prodi Manajemen Pendidikan Islam, STIT Al Urwatul Wutsqo Jombang \\ e-mail: sunardi.ppuw@gmail.com
}

\author{
M. Hamzan \\ Prodi Pendidikan Agama Islam, STIT Al Urwatul Wutsqo Jombang
}

\begin{abstract}
TGKH. Muhammad Zaenudin Abdul Madjid Al Anfanani has what is stated as output a qualified (student), this is evidenced by the success of his students becoming religious and social figures/leaders who take part in various fields. Be it education, politics, economy, da'wah, environment, social. almost all of the students become Tuan Guru with each of the educational institutions they lead. This can not be separated from the integration of knowledge that he initiated. This certainly cannot be separated from the education that has been obtained. The conclusion of the study states that understanding the task of humans as kholifah of Allah on earth, then Islamic education from the perspective of TGKH. Muhammad Zaenudin Abdul Madjid is understood as a process of internalizing knowledge to foster students' awareness of human duties as kholifah ( substitute/leader) on earth, as taught in Islam, by building awareness through upholding the truth, namely Islamic values and teachings. So that the purpose of Islamic education is to foster awareness of students about human duties as kholifah (substitute/leader) on earth, as taught in Islam, by building awareness through upholding the truth, namely the values and teachings of Islam.
\end{abstract}

Key words: Education, Perspective

\section{PENDAHULUAN}

Agama Islam masuk ke pulau Lombok sekitar abad ke 16 disebarkan oleh sunan Prapen putra Sunan Giri Al Fadhal, Sangupati dan lain-lain. Erni Budiyawanti berpendapat bahwa Islam disebarkan oleh raja muslim dari jawa yakni setelah runtuhnya kerajaan Majapahit ${ }^{1}$. Pendapat lain menerangkan bahwa Islam masuk ke Lombok dari dua arah yaitu: melalui utara (Bayan) yang disebarkan oleh Sunan Penggiring dari Jawa Tengah. Ajarannya yang banyak adalah Sufi yang mengarah

\footnotetext{
${ }^{1}$ Erni Budiyawanti, Islam Sasak. Watu Telu Versus Watu Lima, (Yogyakarta: LKIS, 2000), 9.
} 
kepada singkretisme Hindu-Islam. Karenanya mudah diterima secara sukarela oleh masyarakat yang kemudian golongan ini dikenal dengan Wetu Telu. dari arah timur (Lombok Timur) yang disebarkan oleh pendatang terutama pelaut-pelaut Makasar dan para pedagang dari Jawa. Sebagaimana diketahui bahwa pusat kerajaan Selaparang Islam semula di Labuhan Lombok sekarang yang kemudian ke bekas ibukota kerajaan Selaparang Hindu yaitu Watu Parang. Dari sini agama Islam oleh raja Rangke Sari disebarkan keseluruh Lombok.

Tiga abad kemudian semenjak Islam memasuki Lombok, tepatnya pada abad 19 telah lahir tokoh-tokoh agama terkemuka di pulau ini seperti: Tuan Guru Pejeruk (1870), TGKH. Mustafa Sekarbela, Tuan Guru Muhammad Ro’is (Wafat 1867), TGKH. Abdul Hamid Pagutan (1827-1934) (Zakaria, 1998:143-157). Sedangkan abad 20 terdapat nama-nama tokoh penyebar agama Islam seperti: TGH. Muhammad Amin, TGH. Asyari, TGH Mukhtar Abdul Malik, TGH Abdul Karim, TGH. Abdul Hamid, TGH. Ibrahim, TGKH. Muhammad Zaenudin Muhammad Zaenudin Abdul Madjid Al Anfanani (1898-1997), dan masih banyak lagi para tokoh Islam Pulau Lombok. Tokoh-tokoh di atas seluruhnya pernah menimba ilmu di Makkah al Mukkaramah bahkan sebagian di antara mereka telah menjadi pengajar agama Islam di Makkah.

Sekembalinya ke tanah air mereka kemudian mendirikan lembaga-lembaga Pendidikan Islam. Di antara sekian banyak ulama Lombok yang kembali adalah TGKH. Muhammad Zaenudin Muhammad Zaenudin Abdul Madjid Al Anfanani. Ketokohan beliau sebagai seorang individu dan sebagai ulama pada masa itu tidak diragukan lagi. Hal ini terbukti dengan seringnya mendapat tamu-tamu agung yang menyempatkan diri berkunjung ke kediaman beliau baik semasa beliau hayat ataupun setelah meninggal. Adapun tamu-tamu tersebut di antaranya: Syaikh Abdul Aziz Akrom, Syaikh Ismail Utsman, Syaikh Ahmad Akram², Roma Irama (Raja Dangdut), Syaikh Ayub Ali Al Akhdal (Masyaikh Madrasah Shoulatiyah), Syaikh Salim Rohmatulloh (Mudir Madrasah Shoulatiyah), Gusdur (Presiden RI Ke-4 yang juga sempat memberikan piagam penghormatan kepada beliau sewaktu masih menjabat sebagai presiden) Roma Irama, pejabat dari instansi pemerintahan, baik lokal maupun nasional,

\footnotetext{
${ }^{2}$ Nurcholish Madjid, Islam, Doktrin dan Peradaban. (Jakarta: Paramadina, 1992), 12
} 
bahkan juga dari negara sahabat dan perwakilan badan perwakilan internasional seperti WHO, UNICEF, dan lain-lain ${ }^{3}$. Sehingga tidak terlalu berlebihan apabila Dr. H. Ahmad Abd Syakur menempatkan beliau sebagai agen pengembang akulturasi nilainilai Islam melalui Pendidikan Agama Islam Abad 20 di Pulau Lombok.

Kehebatan seseorang sebagai pendidik sebuah lembaga pendidikan dengan struktur sistem pendidikan belum bisa dikatakan sempurna apabila dikemudian hari lembaga dan sistem yang dikembangkannya ternyata output yang dihasilkan tidak mampu berbicara banyak dalam kancah yang lebih besar. Begitu pula sebaliknya, tidak sedikit lembaga pendidikan yang memiliki organisasi kelembagaan yang tidak terlalu rapi, dikatakan hebat, besar serta disegani oleh karena memiliki siswa, mahasiswa yang mampu berbicara banyak di kancah lokal, maupun nasional.

Melihat dari barometer ini maka TGKH. Muhammad Zaenudin Muhammad Zaenudin Abdul Madjid Al Anfanani memiliki apa yang dikemukakan sebagai output (murid) yang mumpuni hal ini dibuktikan dengan keberhasilan para muridnya menjadi tokoh/pemuka agama maupun sosial yang banyak berkiprah dalam berbagai bidang. Baik pendidikan, politik, ekonomi, dakwah, lingkungan, sosial. hampir seluruh santrinya menjadi Tuan Guru dengan masing-masing lembaga pendidikan yang mereka pimpin. Hal tersebut tidak lepas dari integrasi ilmu yang beliau gagas.

Murid beliau yang berkiprah dalam bidang politik antara lain: DR. TGKH. M. Zaenul Majdi, MA (Gubernur NTB 2003-20084. Peraih Gelar Bintang Mahaputra Utama (Muslim, 14: 303), Tokoh Peruahan, sekaligus cucu TGKHMuhammad Zaenudin Abdul Madjid Al Anfanani ), H. Ahyar Abduh (Wali Kota Mataram 20162021) (Abduh, 2007). Dalam bidang pelestarian lingkungan ada TGKH. Hasanain Juaini (Tokoh Perubahan NTB(Kholilurrohman, 2016:10), Peraih Penghargaan Magsaysay ${ }^{5}$ Penerima Penghargaan Kalpataru, sekaligus Pengasuh PP Nurul Haramain NW Narmada) ${ }^{6}$. Adapun murid beliau banyak yang berkiprah dalam bidang pendidikan. Melihat output dari lembaga-lembaga yang beliau dirikan ini maka penulis

\footnotetext{
${ }^{3}$ Iqbal Muhammad Lalu dan Rozi Fahrur, Nabdlatul Wathan dan Pembangunan Sosial-Keagamaan Di Nusa Tenggara Bara. (Bimas: 2014), 14.

${ }^{4}$ Muslihun Muslim, Kiprah Nabdlatul Wathan Dinamika Pemikiran dan Penikiean NW dari Generasi Pertama Hingga Generasi Ketiga, ( Jakarta Timur, Bania Publishing, 2014), 227.

${ }^{5}$ Muslihun Muslim, Kiprah Nabdlatul Wathan...227.

${ }^{6}$ Muslihun Muslim, Kiprah Nabdlatul Wathan...76.
} 
tertarik untuk meneliti lebih dalam terhadap sistem pendidikan yang beliau rintis dan kembangkan tersebut. Didasarkan pada alasan diatas maka penulis berkeinginan melakukan penelitian mengenai kajian pendidikan berbasis keagamaan dengan judul "Pendidikan Islam Perspektif TGKH Muhammad Zaenudin Abdul Madjid Al Anfanani”".

\section{PEMBAHASAN}

\section{A. Pengertian Pendidikan Islam}

Secara umum Pendidikan Islam adalah Pendidikan yang difahami dan dikembangkan dari ajaran dan nilai-nilai fundamental yang terkandung dalam sumber dasarnya yakni Alqur'an dan as-Sunnah. Menurut Langgulung, mengemukakan beberapa istilah Pendidikan Islam diantaranya: at-tarbiyah ad diniyah (pendidikan keagamaan), at ta'limuddin (pengajaran keagamaan), tarbiyyatul muslimin (pendidikan orang-orang Islam), at tarbiyyah fi al Islam (perndidikan didala kalangan orang-orang Islam) at tarbiyyah al Islam iyyah (Pendidikan Islam) ${ }^{7}$.

Sedangkan Chabib Thoha mengemukakan bahwa hakekat Pendidikan Islam adalah proses pemeliharaan sifat dan potensi insani untuk menumbuhkan kesadaran dalam menemukan kebenaran ${ }^{8}$. Sejak wahyu pertama diturunkan dengan program iqra' (membaca), penddikan Islam praktis telah lahir berkembang, dan eksis dalam kehidupan umat Islam, yakni sebuah proses pendidikan dilakukan dengan nama Tuhan yang menciptakan.

\section{B. Dasar dan Tujuan Pendidikan Islam.}

Menurut Ahmad Tafsir dasar Pendidikan Islam terdiri atas:

1. Alqur'an sebagai sumber ajaran Islam pertama,

2. Hadits sebagai sumber ajaran Islam ke dua, dan

3. Akal disuruh untuk digunakan oleh Alqur'an dan Hadits.

Sedangkan tujuan pendidikan Islam sama dengan tujuan Allah SWT menciptakan manusia dan menurunkannya kemuka bumi.

1. Manusia diciptakan oleh Allah SWT supaya menjadi Abdullah (QS. AdzDzariyat/ 51: 56)

\footnotetext{
${ }^{7}$ Muhaimin, Paradigma Pendidikan Islam, (Bandung:Remaja Rosdakarya, 2012), 29.

${ }^{8}$ Marzuki Agus Lalu, Kapita Selekta Pendidikan. (Yogyakarta: Pustaka Pelajar, 1996).11
} 
2. Allah menurunkan manusia ke muka bumi untuk menjadi khalifah fil ardh (QS. Al An'am/ 6:165).

\section{Komponen Dasar Pelaksanaan Pendidikan Islam.}

Bukhari umar memaparkan ada tiga komponen dasar pelaksanaan pendidikan Islam

1. Orang tua.

Orang tua merupakan lembaga pendidikan yang paling pertama bagi anak didik. Didalamnya anak mulai diperkenalkan pada segala sesuatu dalam kegidupan ini dari hal terkecil hingga hal-hal besar. Mulai dari nama-nama benda, melatih memakai baju sendiri, cara makan yang baik, toilet training, melatih motorik halus dan kasar anak, memperkenalkan nilai-nilai kemanusiaan, keadilan, sampai pengenalan akan Tuhan. Oleh karenanya pendidikan pertama didalam keluarga tidak bisa dianggap remeh. Begitu sentralnya peran keluarga sebagai lembaga pendidikan yang pertama bagi anak didik dapat dicermati dari sabda Nabi Muhammad SAW.

2. Pendidik

Pendidik adalah salah satu komponen penting dalan proses pendidikan. Dipundaknya terletak tanggungjawab yang besar dalam upaya mengantarkan anak didik kearah tujuan pendidikan yang dicitakan. secara umum pendidik adalah orang yang bertanggungjawab untuk mendidik. Mereka adalah orang dewasa yang karena hak dan kewajibannya melaksanankan pendidikan. Pendidik dalam pendidikan Islam adalah orang yang bertanggung jawab terhadap perkembangan peserta didik dengan upaya mengembangkan seluruh potensi peserta didik, baik potensi efektif, kognitif, dan psikomotorik.

3. Anak didik.

Anak didik adalah anggota masyarakat yang berusaha mengembangkan potensi diri melalui proses pembelajaran yang tersedia pada jalur, dan jenis pendidikan tertentu. Dalam pendidikan Islam yang menjadi peserta didik

${ }^{9}$ Khoiriyah, MenggagasSosiologi Pendidikan Islam, (Yogyakarta: Teras, 2014)109. 
bukan hanya peserta didik-peserta didik, melainkan juga orang dewasa yang masih berkembang, baik fisik maupun psikis ${ }^{10}$.

\section{ANALISIS}

\section{A. Definisi Pendidikan Islam}

Berangkat dari kesadaran akan amanah yang telah Allah tetapkan sebagai khalifah dimuka bumi ini. Khalifah yang ditugaskan untuk mengelola, menjaga bumi ini, dan tidak berbuat kerusakan, membuat kedamaian, sebagaimana firman Allah SWT QS. Al Baqoroh ayat 30:

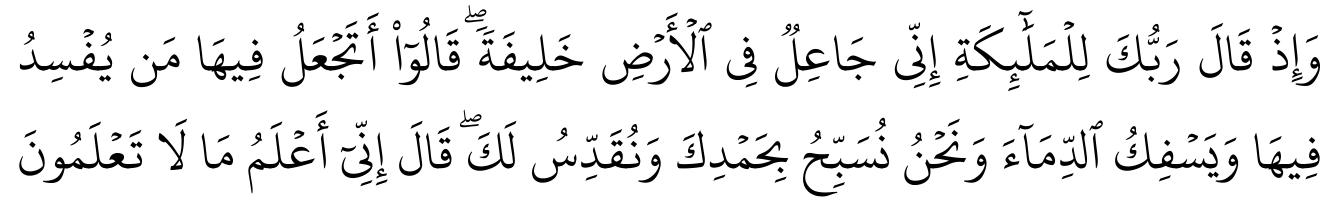

"Ingatlah ketika Tuhanmu berfirman kepada Para Malaikat: "Sesungguhnya aku hendak menjadikan seorang khalifah di muka bumi." mereka berkata: "Mengapa Engkau hendak menjadikan (khalifah) di bumi itu orang yang akan membuat kerusakan padanya dan menumpahkan darah, Padahal Kami Senantiasa bertasbih dengan memuji Engkau dan mensucikan Engkau?" Tuhan berfirman: "Sesungguhnya aku mengetahui apa yang tidak kamu ketahui."

Memahami tugas manusia yang sangat agung ini, maka TGKH. Muhammad Zaenudin Abdul Madjid melalui lembaga pendidikan yang dia dirikan berusaha keras mendidik anak didiknya supaya sadar akan tugas dan fungsinya sebagaimana yang tertera dalam ayat tersebut. Oleh karena itulah pendidikan Islam perspektif dia dapat dimaknai sebagai sebuah proses internalisasi ilmu pengetahuan untuk membina kesadaran peserta didik akan tugas manusia sebagai kholifah (pengganti/pemimpin) dimuka bumi.

Proses internalisasi ilmu pengetahuan ini tidak hanya terwujud dari aktifitas belajar didalam ruangan saja, namun juga memberikan semangat. Hal ini karena beliau memang sosok ulama yang yang selalu bersemangat dalam menuntut ilmu. Wujud semangat tersebut tercatat dalam kisah ketika sorban yang beliau kenakan terbakar disadarinya karena asyiknya belajar.

${ }^{10}$ Umar Bukhari, Ilmu Pendidikan. (Jakarta: Amzah, 2010),103. 
Beliau juga dalam usaha internalisasi ilmu dengan memberikan contoh/teladan.Kita mengetahi sebuah pepatah mengatakan "satu contoh/teladan lebih baik dari seribu nasihat". Beliau adalah sosok yang sangat dikagumi santri dan pecinta, dikarenakan setiap setiap langkah, perkataan, tingkah laku beliau adalah contoh/teladan, itu perihal terkait tata cara dalam menuntut ilmu ataupun berinteraksi sosisal dan sebagainya.

TGKH.Muhammad Zainudin Abdul Madjid Al Anfanani sebagaimana dipaparkan sebelumnya, beliau bukanlah orang yang tidak perduli terhadap ilmu pengetahuan umum, namun sebaliknya.Hal ini dapat kita lihat ketika terbentuknya IPNW (Ikatan Pelajar Nahdlatul Wathan) dan PPLT (Persatuan Pelajar Lombok Tengah).Dari PPLT ini lahir klub olahraga semacam klub olah raga volley, tenis meja, bulu tangkis, kursus fotografi dll.

Pendapat ini diperkuat dengan pendapat Zakia Dradjad, dia menerangkan bahwa pendidikan Islam dapat ditarik kesimpulan dari kegiatan yang dilakukan oleh baginda Nabi Muhammad SAW dalam menyampaikan seruan agama dengan berdakwah, memberi contoh, melatih keterampilan, memberi motifasi, dan menciptakan lingkungan sosial yang mendukung pelaksanaan ide pembentukan pribadi muslim ${ }^{11}$. Pengertian yang tidak jauh berbeda juga dilontarkan oleh Saidah, dia memaparkan bahwa Pendidikan adalah suatu peroses pelatihan dan pengajaran terutama diperuntukan kepada anak-anak ataupun remaja baik disekolah ataupun dikampus dengan tujuan memberikan pengetahuna dan mengembangkan keterampilan ${ }^{12}$.

Pada intinya dari semua definisi diatas bahwa pendidikan Islam adalah sebuah usaha sadar dalam usaha internalisasi ilmu pengetahuan (umum maupun agama) melalui pembelajaran, pelatihan, motifasi sehingga dapat membentuk insan yang berkepribadan muslim, yakni pribadi yag sadar akan fungsinya sebagai seorang kholifah dimuka bumi.

11 Zakiyah Dradjat, Ilmu Pendidikan Islam, (Jakarta:Bumi Aksara, 2014),30.

12 Saidah, Pengantar Pendidikan, (Jakarta:Rajagrafindo, 2016), 1. 


\section{B. Tujuan Pendidikan Islam}

Dapat difahami dari definisi pendidikan Islam yang dijelaskan oleh TGKH. Muhammad Zaenudin Abdul Madjid dimana pendidikan Islam itu adalah sebuah usaha internalisasi ilmu pengetahuan dan nilai-nilai fundamental dari Alqur'an dan As-Sunnah melalui pembelajaran, pelatihan, motifasi untuk membentuk anak didik menjadi pribadi muslim yang sadar akan tugasnya sebagai seorang khalifah. Khalifah yang diberikan amanah mengelola dan menjaga bumi ini, maka tujuan pendidikan dia pun tidak jauh dari definisi tersebut, yakni bagaimana membentuk pribadi anak menjadi pribadi muslim sejati (khalifah). Allah SWT berfirman dalam QS. Al Baqarah ayat 30:

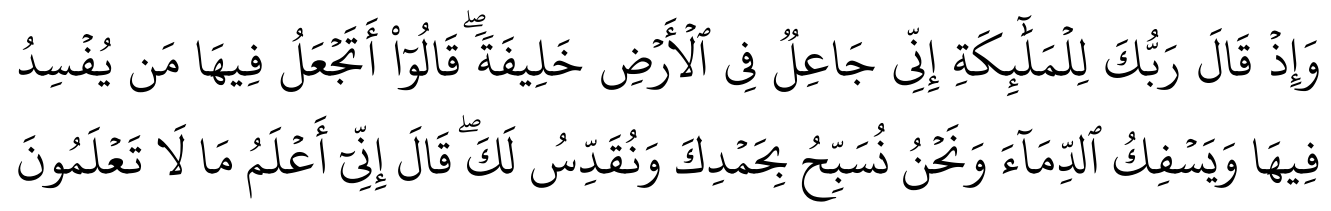

"Ingatlah ketika Tuhanmu berfirman kepada Para Malaikat: "Sesungguhnya aku hendak menjadikan seorang khalifah di muka bumi." mereka berkata: "Mengapa Engkau hendak menjadikan (khalifah) di bumi itu orang yang akan membuat kerusakan padanya dan menumpahkan darah, Padahal Kami Senantiasa bertasbih dengan memuji Engkau dan mensucikan Engkau?" Tuhan berfirman: "Sesungguhnya aku mengetahui apa yang tidak kamu ketahui."

Kesadaran manusia sebagai orang yang diberikan bertanggungjawab atas kemakmuran bumi ini, maka TGKH. Muhammad Zaenudin Abdul Madjid Al anfanani tidak hanya memfokuskan tujuan pendidikannya pada peningkatan rasa beragama pada anak didik semata, tetapi difokuskan pula pada peningkatan intelektual dan bahkan peningkatan skill anak didik, dalam artian tujuan pendidikannya bukan hanya menyangkut aspek emosi beragama, juga menyangkut aspek intelektualitas dan keahlian atau skill.

Harapan para anak didiknya tidak hanya bisa berdakwah diatas mimbarmimbar tapi juga melalui seluruh aspek kebutuhan masyarakat. Hal tersebut secara jelas termaktub dalam tujuan oprasional pesantren Darunnahdlatain Nahdlatul Wathan yang dirumuskannya. Pesantren tersebut bertujuan untuk mencetak anak didik yang memiliki pengetahuan agama dan memiliki pengetahuan umum yang setinggi-tingginya serta memiliki keahlian sebagai guru (mu'allim) ataupun sebagai 
muballigh. Tujuan pendidikan inilah yang kini melalui lembaga-lembaga pendidikan Nahdlatul Wathan telah banyak melahirkan para tokoh agama dan tokoh umum. Sebut saja murid beliau yang berkiprah dalam bidang politik antara lain: DR. TGKH. M. Zaenul Majdi, MA (Gubernur NTB 2003-2008) ${ }^{13}$. Peraih Gelar Bintang Mahaputra Utama ${ }^{14}$, Tokoh Perubahan, sekaligus cucu TGKH Muhammad Zaenudin Abdul Madjid Al Anfanani), H. Ahyar Abduh (Wali Kota Mataram 2016-2021), dalam bidang pelestarian lingkungan ada TGKH. Hasanain Juaini (Tokoh Perubahan NTB) ${ }^{15}$. Peraih Penghargaan Magsaysay Penerima Penghargaan Kalpataru, Sekaligus Pengasuh PP Nurul Haramain NW Narmada) Muhammad Zulkarnaen (Penulis Buku Sang Maulana). Dr. H. M. Mugni Sn., M.Pd., M.Kom. (Penulis Buku Ibu Rumah Tangga Getarkan Lombok), Muhammad Thohri, Lalu Muhyi Abiding Dkk (Penulis Buku Kagungan Prbadi Sang Pecinta, Maulana)Adapun murid beliau yang berkiprah dalam bidang pendidikan antara lain: H. Muhammad Suhaidi (Pendiri Lemaga Pendidikan NW Jakarta), TGH. Najamuddin Makmun (Pendiri PP Darul Mujahidin Praya), TGH. H.L. Muhammad Faisal (Pimpinan PP Manhalul Ulum Praya), TGH. Muhaddis Adul Haris (Pendiri Madrasah Nurul Yaqin Praya), TGH. Dahmuruddin (Pengasuh PP Darun Nahdlatain NW Panor), Syaikh M. Adnan (menjadi Syaikh Di Madrasah Shoulatiyah Makkah), TGH. Afifudiin Adnan ( Pendiri PP Al Mukhtariyah Mamben), TGH. M zaenudin Masyhur MA (Pendiri PP Mambaul Bayan Sakra), TGH. L. M. Yusuf Hasyim Lc (Pendiri Pondok Pesatren Darunnahdlah NW Korleko Lomok Timur), TGH. Mustafa Umar (Pendiri salah satu PP ternama di pulau Lomok yakni PP Al Aziziyah Kapek Gunung Sari), dan masih banyak lagi murid-murid beliau yang berkiprah dalam semua bidang yang tidak bisa penulis sebutkan secara rinci dalam penelitian ini

Pendapat ini selaras dengan apa yang dikemukakakan khoriyah Bahwa Allah memerintahkan kita untuk tidak hanya fokus pada urusan akhirat saja

\footnotetext{
${ }^{13}$ Muslihun Muslim, Kiprah Nabdlatul Wathan...227

${ }^{14}$ Muslihun Muslim, Kiprab Nabdlatul Wathan...303.

${ }^{15}$ Kholilurrohman, TGKH. Hasanain Juaini dari Kitab Kuning Menuju Gerakan Kitab Hijau, (Ponpes Nurul Haramain NW, Narmada, 2016), 10.
} 
(Abdullah), sampai melupakan tanggungjawabnya sebagai pemelihara dan orang yang memakmurkan bumi ini.

\section{Materi dan Kurikulum Pendidikan Islam}

Ketika TGKH. Muhammad Zainuddin Abdul Madjid Al Anfanani mengawali perjuangannya dalam bidang pendidikan, TGKH. Muhammad Zainuddin Abdul Madjid Al Anfanani menyadari bahwa tidak semua kurikulum pendidikan dari barat itu buruk, jika dalam hal mata pelajaran materi umum, maka pendidik tidaklah disyaratkan muslim. Non muslim pun bisa dirangkul. Fenomena ini adalah implementasi dari perpaduan antara sistem pendidikan klasikal modern dalam pendidikan Islam yang dikonsepsikannya.

TGKH. Muhammad Zaenudin Abdul Madjid Al anfanani tidak memperkenankan adanya dikotomi ilmu agama dan umum yang berasal dari barat. Karenanya kurikulum pendidikan Islam TGKH. Muhammad Zaenudin Abdul Madjid Al anfanani tidak hanya memberikan materi agama, seperti Fiqih, ilmu Tauhid, ilmu Akhlak, dan ilmu-ilmu alat yang meliputi bahasa Arab, Nahwu, Sharaf, Balaghah pada anak didiknya, juga materi materi umum, seperti ilmu berhitung/matematika, ilmu biologi, ilmu sejarah, serta berbagai pendidikan keterampilan dan ilmu lainnya. Kusus materi ke-nw-an adalah materi urgen disetiap lembaga pendidikan di nahdlatul wathan.Sehingga para santri yang keluar dari lembaga-lembaga Nahdlatul Wathan mampu berkontribusi untuk ummat melalui aspek-aspek gerakan organisasi yakni pendidikan, sosial dan dakwah. ‘

Kurikulum tersebut sangat sesuai dengan pendapat yang dikutip oleh Sohebul Hasan dalam penelitiannya, bahwa kurikulum yang baik dan relevan dalam rangka mencapai tujuan Pendidikan Islam adalah yang bersifat intergrated dan komprehensif serta menjadikan Alqur'an dan Hadits sebagai sumber utama dalam penyusunannya.

\section{Metode Pendidikan Islam.}

Metode yang digunakan sangat bervariasi, bukan hanya menggunakan metode halaqah dimana para santri duduk mengelilingi seorang guru, tetapi juga menggunakan: 
1. Metode Penugasan. Metode ini dalam arti seorang guru memerintahkan anak didik untuk meneliti, melakukan sesuatu (dalam proses pendidikan ) Sedangkan hasil diperiksa pendidik dan dipertanggungjawakan oleh anak didik. Sesuai firman-Nya QS. Al Muddatsir ayat1-7. TGKH. Muhammad Zainudin Abdul Madjid Al Anfanani dalam mengaplikasikan metode tersebut tidak hanya dalam bentuk klasikal namun juga dalam pentuk penugasan pengabdian. Metode ini telah mampu melebarkan sayap dakwah Nahdlatul Wathan dalam usaha membangun ummat.Penugasan melakukan pengabdian tersebut dilakukan ke pulau-pulau senusantara seperti Kalimantan, Sumbawa, Sulawesi, Bali, Jawa dll.

2. Metode Nasihat adalah pendidik memberikan nasihat agar peserta didik dapat mengambil ibrah dari nasihat yang disampaikan pendidik. Miftahul Jannah menerangkan bahwa Metode ini ia sebut sebagai metode Mauidzoh Hasananah. Metode ini adalah pemberian nasihat dan peringatan tentang kebaikan dan kebenaran dengan cara yang lembut sehingga dapat menusuk kalbu dan tergugah untuk mengamalkannya. Salah satu contoh dapat dilihat dari bait dibawah. Metode ini beliau aplikasikan baik secara lisan yakni melalui pengajian-pengajian, halaqoh, maupun dari tulisan. Sebagaimana yang beliau tuangkan dalam bentuk lagu-lagu perjuangan dan buku kecil yang berjudul "Wasiat Renungan Masa".

3. Metode Diskusi adalah suatu metode yang digunakan dengan bertukar fikiran atau bermusyawarah menemikan jalan/solusi yang paling baik dan tepat..

4. Metode Keteladanan. Metode ini dapat difahami dari karakteristik seorang pendidik dimana tingkah laku seorang pendidik akan selalu menjadi soorotan anak didik. Karenanya seorang pendidik dibina untuk bisa memperlihatkan akhlak dan budi pekerti yang baik agar bsia dijadikan contoh yang baik oleh anak ddik. pendidik merupakan Metode tersebut banyak ditemukan dalam berbagai pengajian, fatwa dia. Muchtar menjelaskan bahwa metode keteladanan adalah suatu metode pendidikan dengan cara memberikan contoh yang baik kepada para pesera didik, baik dalam ucapan maupun dalam perbuatan. Metode ini sangat penting karena berkaitan dengan aspek akhlak dalam kawasan efektif yang terwujud dalam bentuk tingkah laku. Untuk mempertegas keteldanan 
Rasululloh,lebih lanjut Alqur'an menjelaskannya secara tersear didalam berbagai ayat dalam QS. Al-Ahzab ayat 21.

5. Metode Pembiasaan membaca Hizib Nahdlatul Wathan, Barzanji pada malammalam ataupun momentum tertentu, Salawat Nahdlatain sebagai doa utama sebelum masuk kelas dan doa pusaka sebelum pulang. dan lain sebagainya adalah contoh penerapan Metode ini baik dimadrasah Nahdlatul Wathan Jakarta ataupun di Lombok. Beberepa metode memiliki kesamaman dengan metode pendidikan Islam perspektif Abdurrohman Al Nahlawi yang dikutip oleh Toto Suharto antara lain: metode ceramah (hiwar), kisah (Qur'any ataupun Nabawi), perumpamaan (amtsal), keteladanan (uswah), latihan dan pengalaman, pelajaran (ibrah), peringatan (mauidzob), penghargaan (targhib), dan hukuman $(\text { tarbib })^{16}$.

\section{E. Pendidik.}

Pendidik adalah salah satu komponen penting dalan proses pendidikan. Dimana seorang sebagai tokoh sentral dalam proses belajar mengajar. Selanjutnya TGKH. Muhammad Zaenudin Abdul Madjid mengatakan bahwa "pendidik itu adalah orang jalan kesyurga". Dengan demikian terdapat tanggung jawab yang tidak ringan dipundak seorang pendidik. Bagaimana caranya anak didiknya menjadi masyarakat yang baik, bermanfaat bagi sesama yakni dalam rangka memahami fungsi dan tugasnya sebagai hamba, dan makhluk sosial..

Hal tersebut didukung dengan pendapat Suryo Subroto. Dia menerangkan bahwa Pendidik adalah orang yang bertanggungjawab memberikan pertolongan kepada anak didik dalam perkembangan jasmani dan rohaninya, agar mencapai tingkat kedewasaan, mandiri memenuhi tugasnya sebagai seorang kholifah. Kholifah disini tidak lepas pemaknaannya dengan makhluk tuhan, makhluk sosial dan individu ${ }^{17}$.

Karakteristik pendidik perspektif TGKH. Muhammad Zainuddin Abdul Madjid Al Anfanani, secara umum tergambar dalam lagu berjudul Satui Jati dia

16 Toto Suharto, FilsafatPendidikan Islam, (Jakarta: ArRuz Media, 2011), 136.

${ }^{17}$ Suryo Subroto, Beberapa Aspek Dasar-Dasar Kependidikan, (Jakarta: Rineka Cia, 2010), 18. 
menegaskan mengenai identitas seorang pendidik sebagai tempat untuk berguru dan menimba ilmu. Karakteristik wajib yang dimiliki seorang pendidik ada empat yakni Alim (kaya ilmu), Sholeh (ibadah hebat), ikhlas (perjuangan tanpa pamrih, tidak ada tujuan selain keridaan Allah), dan ciri terakhir "tegak" yakni memiliki sikap tegas dan jelas terhadap agama, tidak ragu dan berhianat selain untuk tujuan agama.

Lebih lanjut TGKH. Muhammad Zaenudin Abdul Madjid Al anfanani membagi karakteristik seorang pendidik sebagai berikut:

a. Seorang pendidik hendaknya memiliki aqidah yang jelas dan menekankan pada keyakinan, ikhlas dan istiqomah.

b. Seorang pendidik hendaknya memiliki faham keagamaan ahlussunnah wal jama'ah, terutama bagi pendidik yang mengampu materi agama;

c. Seorang pendidik hendaknya bersifat jujur. Dapat kita lihat dalam salah satu bait syair dia berbunyi:

Setan iblis terpukul mundur

Usaha mereka terbakar hancur

Dengan bantuan albayyu syakur

Dibimbing oleh pembimbing jujur

Sangat beralasan ketika jujur menjadi salah satu karakteristik seorang pendidik. Dikarenakan seorang pendidik adalah sumber ilmu. Seorang pendidik hendaknya disamping memiliki jiwa pengabdian (dedication) yang tinggi juga memiliki ilmu yang luas dan karakteristik-karaktaristik yang lain. Dalam hal ini, kita bisa sedikit berkaca pada karaktaristik pendidik dalam perspektif $\mathrm{KH}$. Hasyim Asy'ary. Dia memaparkan karakteristik seorang pendidik sebagai berikut:
a. Selalu istiqomah dalam muroqobah pada Allah.
b. Senantiasa bersikap khouf (takut kepada Allah).
c. Senantiasa bersikap tenang.
d. Bersiap warok.
e. Takwa kepada Allah SWT.
f. Berilmu.
g. Berakhlak baik 


\section{F. Anak didik}

Dalam pendidikan Islam yang menjadi peserta didik bukan hanya peserta didik-peserta didik, melainkan juga orang dewasa yang masih berkembang, baik fisik maupun psikis. Karakteristik anak didik ini banyak dipengaruhi oleh konsep Ta'lìm al-Muta'allim yang ditawarkan al-Zarnujî, bahwa pencari ilmu berniat mencari keridlaan Allah, kebahagiaan akhirat, menghilangkann kebodohan diri dan orang lain, menghidupkan dan menegakkan agama Islam. Keseluruhannya tampak melalui sikap dan perilaku fisik dan non-fisik dalam keseharian santri Pesantren NW. Karakterisitk anak didik lebih lanjut diabagi kedalam beberap macamantara lain sebagai berikut:

1. Beraqidah ahlussunnah wal jama'ah dan bermazhab Syafi'i;

2. Tidak dibolehkan menghabiskan waktunya dengan sia-sia. Ada pepatah mengatakan "the time is money" waktu adalah uang. Ini menagajarkan pada setiap anak didik untuk menghargai waktu. Kita juga bisa temukan dalam Al

qur'an, banyak yang menerangkan akan pentingnya menjaga atau memanfaatkan waktu. Surat al 'asr, dhuha, al falaq. Melalui semua surat ini Allah ajarkan akan pentingnya waktu.

3. Seorang anak didik haruslah lebih mendahulukan yang wajib dari pada yang sunnah. Artinya, seorang anak didik ketika menjadi pelajar maka yang wajib baginya adalah belajar bukan mengutamakan yang lain sekalipun itu hal yang baik (dzikir). Oleh karena itulah TGKH. Muhammad Zaenudin Abdul Madjid Al anfanani menekankan kepada anak didiknya kalau sedang jadi pelajar hendaknya belajar $80 \%$ dan wirid / dzikir 20\%.

4. Anak didik hendaknya memiliki jiwa yang berani, ikhlas, yakin, istiqomah dan memiliki akhlak al-karimah. Berani menegakkan agama, memperjuangkan kebenaran dan memerangi kebodohan dengan segala resiko. Perjalanan hidup diri dan keluarga besar TGKH. Muhammad Zaenudin Abdul Madjid Al anfanani adalah contoh nyata keberanian dalam memperjuangan kebenaran benar-benar menjadi misi perjuangan. Memimpin pemberontakan pada pasukan kaum penjajah belanda salah satu contoh. Iklas dalam berjuang tidak lepasdari perhatian beliau. Pembakaran Pesantren yang dibangun susah payah, pengusiran, terror yang didapat, dan tanpa bayaran tidaklah menjadi 
penyebab surutnya giroh perjuanganinilah bentuk keikhlasan yang beliau tanamkan. Yakin bahwa perjuangan akan dibalas dengan sepadan telah menjadi motivasi perjuangan. Semakin lemah dan sedikit kita berkorman untuk perjuangan maka sebanyak itulah ganjaran yang akan didapat. Istiqamah dalam perjuangan. Keteguhan hati menghadapi berbagai gangguan, intimidasi pemuka saat itu menjadi acuan bahwa perjuangan butuh keistiqomahan.

5. Anak didik hendaknya memiliki sifat jujur. Jujur adalah sebuah sikap yang selalu berupaya menyesuaikan atau mencocokan antara Informasi dengan fenomena atau realitas.

6. Tawadduk. Tawadhu ialah merendahkan diri dan berlaku lemah lembut. Dan ini tidak akan mendongkrak pelakunya menjadi terpuji melainkan bila dibarengi karena mengharap wajah Allah azza wa jalla. Syaikhul Islam Ibnu Taimiyah mengatakan: "Kalau sekiranya ada orang bersikap tawadhu agar Allah Shubhanahu wa ta'alla mengangkat derajatnya dimata orang, maka ini belum dikatakan telah merengkuh sifat tawadhu, karena maksud utama perilakunya itu didasari agar mulia dimata orang, dan sikap seperti itu menghapus tawadhu yang sebenarnya"

7. Pandai bersyukur. Secara bahasa syukur adalah pujian kepada yang telah berbuat baik atas apa yang dilakukan kepadanya. Syukur adalah kebalikan dari kufur. Hakikat syukur adalah menampakkan nikmat, sedangkan hakikat kekufuran adalah menyembunyikannya ${ }^{18}$.

8. Menjaga hati. Menjaga hati adalah berusaha menjauhkan hati dari segala sesuatu yang meracuninya, merusaknya, atau membutakan hati.

9. Taat, Taat sering disamakan artinya dengan tunduk, setia dan patuh. Yang dimaksud dengan taat adalah tunduk dan patuh terhadap perintah atau larangan seseorang atau peraturan yang berlaku. Sikap taat kepada Allah disebut dengan takwa.

${ }^{18}$ Amir An-Najar, Psikoterapi Sufistik dalam Kebidupan Modern, Terj. Ija Suntana, (Bandung: Mizan Publika, 2004), 90 . 
10. Setia. Setia artinya memiliki komintenn kuat yang ditunjukkan dengan cara selalu ada dalam setiap keadaan, tidak berkhianat dan berbohong, menjunjung persatuan. Dalam buku wasiat renungan masa setia ditujukan kepada guru, organisasi, agama dan bangsa.

11. Kompak. Kompak berarti bersatu padu (dalam menanggapi atau menghadapi suatu perkara dan sebagainya).

Berbagai macam karaktersitikanak didik tersebut diperkuat dengan pendapat karya KH. Hasyim Asy'ary dalam kitab Adabul Alim Wa Mutaalim yang berisikan beberapa karakteristik anak didik antara lain:

1. Membersihkan hati dari akhlak yang tercela

2. Membaguskan niar

3. Manajemen waktu baik untuk belajar,tidur, istirahat, rihlah, dll

4. Bersikap qonaah

5. Pandai memanajemen waktu

6. Tirakat

7. Bersikap wira'i

8. Menghindari makanan penyebab lupa

9. Meminimalisir pergaulan yang kurang bermanfaat

Adapun Karakeristik anak didik pada pendidik

1. Beristikhoroh dalammencari pendidik

2. Mencari pendidik yang ahli

3. Pmengikuti/patuh dan bertatakrama terpuji

4. Memuliakan pendidik (pikiran, perkataan dan perbuatan)

5. Husnudzon

6. Menunjukkan semangat belajar

\section{G. Lembaga Pendidikan Islam.}

Tidak dijelaskan secara eksplisit tentang definisi sebuah lembaga pendidikan Islam. Namun dia sangatlah menaruh perhatian besar terhadap lembaga-lembaga pendidikan Islam. Hal demikian terlihat dari kuantitas lembaga pendikan yang dia dirikan maupun yang didirikan oleh santri. Pada tahun 1953 telah berdiri 66 lembaga penddikan formal maupun non formal. Adapun yang 
formal mulai dari taman kanak-kanak, Sekolah Dasar, Madrasah Ibtidaiyah, MTs Muallimin, MTs Muallimat, MA Mualimin, MA Muallimat, SLTP, SMU, SMK, MA Keterampilan, MA Keagamaan Putra Putri, Perguruan Tinggi dan PONPES. Sedangkan yang tidak formal, yaitu MDQH, lembaga dakwah dan lembaga sosial lainnya dibawah naungan organisasi yang dia dirikan bernama Nahdlatul Wathan (NW).

Jika kita berpijak pada pendapat Muliawan Jasa Ungguh dan Moch. Eksan tentang jenis-jenis lembaga pendidikan Islam yang diantaranya adalah Masjid, Pondok Pesantren, Madrasah, Taman Pendidikkan Qur'an, Sekolah Islam, bahkan perkumpulan- perkumpulan kajian keIslam anan (Ungguh, 2015: 214), maka tidak berlebihan TGKH. Muhammad Zaenudin Abdul Madjid memiliki semua jenis lembaga pendidikan tersebut tersebut.

\section{KESIMPULAN}

Memahami tugas manusia sebagai khalifah Allah dimuka bumi, maka pendidikan Islam perspektif TGKH. Muhammad Zaenudin Abdul Madjid difahami sebagai sebuah proses internalisasi ilmu pengetahuan untuk membina kesadaran peserta didik akan tugas manusia sebagai kholifah (pengganti/pemimpin) di muka bumi, sebagaimana yang diajarkan dalam agama Islam, dengan membangun kesadaran melalui penegakan kebenaran, yakni nilai dan ajaran Islam .

\section{DAFTAR PUSTAKA}

Agus Lalu, Marzuki, Kapita Selekta Pendidikan. Yogyakarta: Pustaka Pelajar, 1996.

An-Najar, Amir, Psikoterapi Sufistik dalam Kehidupan Modern, Terj. Ija Suntana, Bandung: Mizan Publika, 2004.

Budiyawanti, Erni, Islam Sasak Watu Telu Versus Watu Lima, Yogyakarta: LKIS, 2000.

Bukhari, Umar, Imu Pendidikan. Jakarta: Amzah, 2010.

Dradjat, Zakiyah, Ilmu Pendidikan Islam, Jakarta:Bumi Aksara, 2014.

Iqbal Muhammad Lalu dan Rozi Fahrur, Nabdlatul Wathan dan Pembangunan SosialKeagamaan Di Nusa Tenggara Bara. Bimas: 2014. 
Khoiriyah, MenggagasSosiologi Pendidikan Islam, Yogyakarta: Teras, 2014.

Kholilurrohman, TGKH. Hasanain Juaini dari Kitab Kuning Menuju Gerakan Kitab Hijau, Ponpes Nurul Haramain NW, Narmada, 2016.

Madjid, Nurcholish, Islam, Doktrin dan Peradaban. Jakarta: Paramadina, 1992.

Muhaimin, Paradigma Pendidikan Islam, Bandung:Remaja Rosdakarya, 2012.

Muslim, Muslihun, Kiprah Nabdlatul Wathan Dinamika Pemikiran dan Penikiean NW dari Generasi Pertama Hingga Generasi Ketiga, Jakarta Timur, Bania Publishing, 2014.

Saidah, Pengantar Pendidikan, Jakarta:Rajagrafindo, 2016.

Subroto, Suryo, Beberapa Aspek Dasar-Dasar Kependidikan, Jakarta: Rineka Cia, 2010.

Suharto, Toto, FilsafatPendidikan Islam, Jakarta: ArRuz Media, 2011. 